\title{
Особенности температурной зависимости удельного контактного сопротивления диффузионных кремниевых структур $\mathrm{Au}-\mathrm{Ti}-\mathrm{Pd}-n^{+}-n-\mathrm{Si}$
}

\author{
(C) А.Е. Беляев ${ }^{1}$, Н.С. Болтовец ${ }^{2}$, В.П. Кладько ${ }^{1}$, Н.В. Сафрюк-Романенко ${ }^{1}$, А.И. Любченко ${ }^{1}$, \\ В.М. Шеремет ${ }^{1}$, В.В. Шинкаренко ${ }^{1,}$, А.С. Слепова ${ }^{2}$, В.А. Пилипенко ${ }^{3}$, \\ Т.В. Петлицкая ${ }^{3}$, А.С. Пилипчук ${ }^{4}$, Р.В. Конакова ${ }^{1}$, А.В. Саченко ${ }^{1}$ \\ ${ }^{1}$ Институт фризики полупроводников им. В.Е. Лашкарева Национальной академии наук Украины, \\ 03028 Киев, Украина \\ ${ }^{2}$ ГП НИИ „Орион“, \\ 03057 Киев, Украина \\ ${ }^{3}$ ОАО „ИНТЕГРАЛ“ - управляющая компания холдинга „ИНТЕГРАЛ“, \\ 220108 Минск, Республика Беларусь \\ ${ }^{4}$ Институт физики Национальной академии наук Украины, \\ 03028 Киев, Украина \\ ฯ E-mail: shynkarenko@gmail.com \\ (Поступила в Редакцию 23 октября 2018 г. \\ В окончательной редакции 6 ноября 2018 г. \\ Принята к публикации 12 ноября 2018 г.)
}

\begin{abstract}
Измерены экспериментально и описаны теоретически температурные зависимости удельного контактного сопротивления кремния $\rho_{\mathrm{c}}$ со ступенькой легирования. Измерения проведены в диапазоне температур от 4.2 до $380 \mathrm{~K}$. Установлено, что контакты исследованных структур $\mathrm{Au}-\mathrm{Ti}-\mathrm{Pd}-n^{+}-n$-Si являются омическими. Показано, что минимальная величина $\rho_{\mathrm{c}}$ реализуется при $T=75 \mathrm{~K}$. Ее значение растет как при понижении температуры (вследствие эффекта вымораживания), так и при повышении температуры (из-за наличия слоя обогащения электронами на границе с объемом). Установлено, что в приконтактной области, в слое толщиной порядка микрона, происходит сильное уменьшение объемной концентрации электронов вследствие компенсации кремния глубокими акцепторами, возникающими из-за образования достаточно большой концентрации вакансий при релаксации напряжений и появления большой плотности дислокаций, а также вследствие их диффузии от контакта после прогрева до $450^{\circ} \mathrm{C}$. Данные о существовании дефектов вакансионного типа подтверждены рентгеновскими измерениями. Из рентгеновских измерений оценена также плотность дислокаций в исследованных структурах.
\end{abstract}

DOI: 10.21883/FTP.2019.04.47445.9012

\section{1. Введение}

До недавнего времени научные представления об омических контактах к полупроводникам базировались на теории контакта металл-полупроводник [1]. В случае полупроводника $n$-типа рассматривается низкобарьерный контакт Шоттки с работой выхода электронов из металла, меньшей, чем работа выхода электрона из полупроводника, вольт-амперная характеристика такого контакта линейна и симметрична. При этом удельное контактное сопротивление $\rho_{\text {c }}$ уменьшается с ростом температуры для термоэлектронного и термополевого механизмов токопереноса в контакте и не зависит от температуры для туннельного механизма.

Однако имеются экспериментальные работы по исследованию омических контактов, в которых наблюдается увеличение $\rho_{\mathrm{c}}$ с ростом температуры, не описываемое известными теоретическими моделями $[2,3]$.

Авторами данной работы была предложена и экспериментально подтверждена модель формирования омического контакта, объясняющая рост $\rho_{\mathrm{c}}$ с увеличением температуры в омических контактах, к монокристаллическому $n^{+}-\mathrm{Si}$ с уровнем легирования кремния $\sim 10^{19} \mathrm{~cm}^{-3}$ путем прохождения тока через металлические шунты, совмещенные с дислокациями, у торцов которых (шунтов) возникает обогащающий изгиб зон. В этом случае реализуется принципиально небарьерный механизм токопереноса [4,5]. Природа дислокаций, возникающих в приконтактной области, чаще всего связывается с релаксацией механических напряжений в контакте. Это было показано на примере сплавных контактов к $\mathrm{Si}$, соединениям $\mathrm{A}^{\mathrm{III}} \mathrm{B}^{\mathrm{V}}$ [6] или омических контактов к тринитридным гетероструктурам [7], выращенных на чужеродных подложках. Плотность дислокаций в таких гетероструктурах составляет $10^{7}-10^{11} \mathrm{~cm}^{-2}$ для разных типов приборных структур. Плотность дислокаций в сплавных контактах к $\mathrm{Si}$ и соединениям $\mathrm{A}^{\mathrm{III}} \mathrm{B}^{\mathrm{V}}$ достигает $10^{8} \mathrm{~cm}^{-2}$.

Как известно, в современных полупроводниковых приборах омический контакт создается к специально легированному $n^{+}$-слою (или $p^{+}$-слою), к так называемой ступеньке легирования, полученной диффузией, ионным легированием или эпитаксией. Генерация структурных дефектов в этом слое в зависимости от уровня легирования и их роль в формировании и свойствах омических контактов подробно не изучались. В то же время знание 
зависимости $\rho_{\mathrm{c}}(T)$ для приборов, рабочие температуры которых превышают $300 \mathrm{~K}$, является необходимым. Это

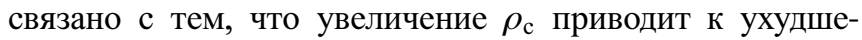
нию их параметров, например, снижает эффективность и добротность СВЧ диодов [8]. Представляет также интерес значение $\rho_{\mathrm{c}}$ в области гелиевых температур, например для датчиков температур [9], других типов приборов криогенной электроники [10]. Поэтому как экспериментальные, так и теоретические исследования зависимости $\rho_{\mathrm{c}}(T)$ в омических контактах и специфика структурных дефектов в приконтактном слое представляются актуальными.

Так как электрофизические, структурные и механические свойства кремния хорошо изучены и он до сих пор является основным полупроводниковым материалом электронной промышленности, именно омические контакты со ступенькой легирования в $\mathrm{Si}$ выбраны нами в качестве модельных для исследования особенностей температурной зависимости $\rho_{\mathrm{c}}$.

\section{2. Образцы и методы исследования}

В данной работе ступенька легирования получалась методом диффузии фосфора в кремниевую пластину $n$-типа (100) с $\rho=7.5 \mathrm{Oм} \cdot$ см, толщиной 400 мкм, плотностью дислокаций $\sim 10^{5} \mathrm{~cm}^{-2}$. Глубина диффузионного слоя составляла 0.5 мкм. Диффузия осуществлялась при $T=900,925,950$ и $970^{\circ} \mathrm{C}[11]$.

Удельное контактное сопротивление омических контактов $\mathrm{Au}(150$ мкм $)-\mathrm{Ti}(60$ нм $)-\operatorname{Pd}(20$ нм $)-n^{+}-n$-Si измерялось в вертикальной геометрии в диапазоне температур $4.2-300 \mathrm{~K}$ на тестовых структурах, собранных в корпус.

Пленки $\mathrm{Au}, \mathrm{Ti}$ и $\mathrm{Pd}$ создавались вакуумным напылением металлов в одном технологическом цикле на подогретую до $350^{\circ} \mathrm{C}$ подложку. Омический контакт на основе $\mathrm{Pd}_{2} \mathrm{Si}$ формировался непосредственно в процессе напыления. Вжигание контактов осуществлялось при $T=350^{\circ} \mathrm{C}$ (образцы, прошедшие диффузию при $T=900$ и $925^{\circ} \mathrm{C}$ ) и $T=450^{\circ} \mathrm{C}$ (образцы, прошедшие диффузию при 950 и $970^{\circ} \mathrm{C}$ ) в вакууме $10^{-4}$ Па в течение 10 мин [11]. Структурное совершенство образцов исследовалось методом высокоразрешающей рентгеновской дифракции на дифрактометре Panalitycal X'Pert PRO MRD [11,12].

\section{3. Результаты измерения $\rho_{\mathrm{c}}$ и их обсуждение}

На тестовых TLM структурах были измерены температурные зависимости $\rho_{\mathrm{c}}$. Типичная зависимость $\rho_{\mathrm{c}}(T)$, измеренная в интервале температур $12.5-400 \mathrm{~K}$, приведена на рис. 1 . Видно, что на зависимости $\rho_{\mathrm{c}}(T)$ имеется минимум при $T=75 \mathrm{~K}$. По обе стороны от минимума $\rho_{\mathrm{c}}$ возрастает более быстро при понижении температуры, т.е. $\rho_{\mathrm{c}}(T)$ отличается от зависимостей

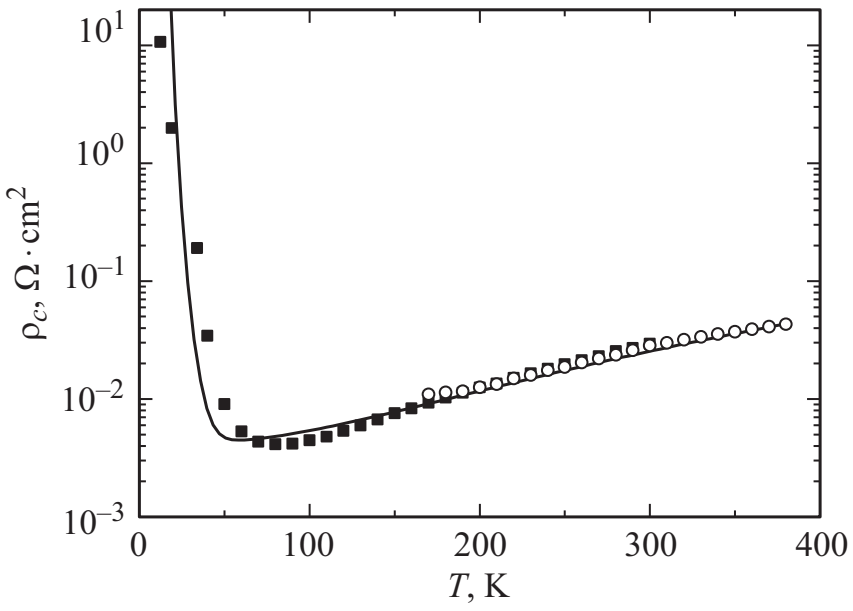

Рис. 1. Экспериментальные и теоретические зависимости $\rho_{\mathrm{c}}(T)$ для кремния со ступенькой легирования. $n_{2}=$ $=1.6 \cdot 10^{13} \mathrm{~cm}^{-3}, A^{*}=112 \mathrm{~A} \cdot \mathrm{cm}^{-2} \cdot \mathrm{K}^{-2}, N_{\mathrm{c}}=2.8 \cdot 10^{19} \mathrm{~cm}^{-3}$.

$\rho_{\mathrm{c}}(T)$, предсказываемых теорией [1]. При этом ни термоэлектронный механизм токопереноса, ни термополевой механизм не объясняют зависимость $\rho_{\mathrm{c}}(T)$ в области гелиевых температур.

Рассмотрим модель омического контакта со ступенькой легирования в приконтактной области, когда в сильно легированном $n^{+}$- слое имеет место вырождение электронов. Именно этот случай реализуется в технологии кремниевых полупроводниковых приборов, в том числе ЛПД. При этом толщина сильно легированной области $W_{n^{+}}$с концентрацией электронов $n_{1}^{+}$превышает толщину слоя Шоттки $W_{\mathrm{Sch}}$, а уровень легирования больше, чем эффективная плотность состояний электронов в зоне проводимости $N_{\mathrm{c}}$. Это и означает, что в сильно легированной области имеет место вырождение электронов.

В настоящей работе произведен аналитический расчет зависимости $\rho_{\mathrm{c}}(T)$ для омических контактов со ступенькой легирования на основе $\mathrm{Si}$ для предельного случая, когда зонная диаграмма контакта имеет вид, приведенный на рис. 2.

Как видно из рисунка, в рассматриваемом случае толщина сильно легированной области $W_{n^{+}}$с концентрацией электронов $n_{1}^{+}$превышает толщину слоя Шоттки $W_{\mathrm{Sch}}$, т.е. $W_{n^{+}}>W_{\text {Sch }}$, а уровень легирования больше, чем эффективная плотность состояний электронов в зоне проводимости $N_{\mathrm{c}}$, т.е. $n_{1}^{+}>N_{\mathrm{c}}$. Это означает, что в сильно легированной области имеет место вырождение электронов. Объемная концентрация электронов в слабо легированной области при этом равняется $n_{2}$.

В этом случае удельное контактное сопротивление может быть представлено в виде последовательного соединения двух сопротивлений:

$$
\rho_{\mathrm{c}}=\rho_{\mathrm{c} 1}+\rho_{\mathrm{c} 2},
$$

где $\rho_{\mathrm{c} 1}-$ удельное контактное сопротивление, связанное с термополевым прохождением электронов через ба- 


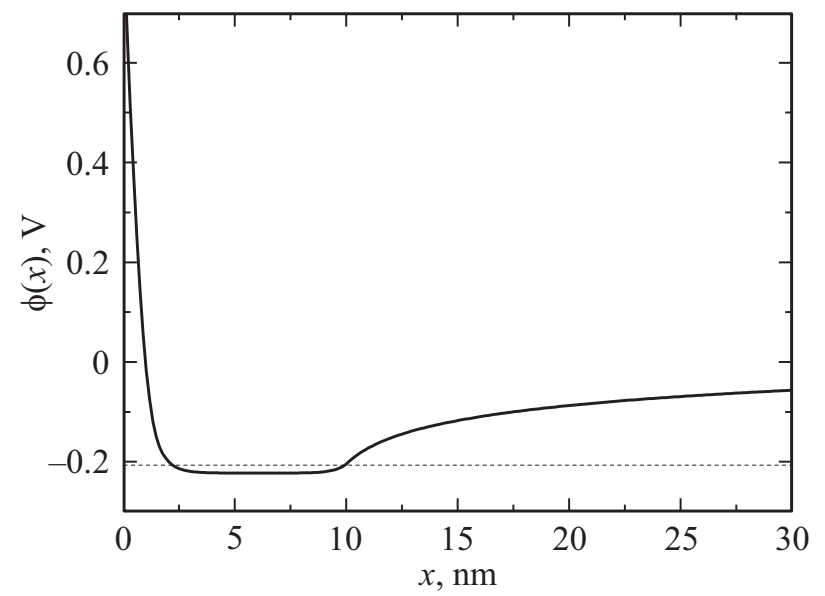

Рис. 2. Зонная диаграмма омического контакта со ступенькой легирования $n^{+}$-n-типа с параметрами: $n^{+} \sim 5 \cdot 10^{20} \mathrm{~cm}^{-3}$, $n_{2} \sim 10^{15} \mathrm{~cm}^{-3}, W_{n^{+}} \sim 0.01$ мкм.

рьер на границе сильно легированного полупроводника и металла, а

$$
\rho_{\mathrm{c} 2}=\frac{k N_{\mathrm{c}}}{q A^{*} T n_{2}}\left(1+\frac{L_{\mathrm{D}} A^{*} T}{k \mu_{n} N_{\mathrm{c}}}\right)
$$

- эффективное удельное контактное сопротивление слабо легированной области в предельном случае, когда энергетическая диаграмма контакта имеет вид, приведенный на рис. 2. Здесь $q-$ заряд электронов, $k-$ постоянная Больцмана, $A^{*}$ - эффективная постоянная Ричардсона, $\mu_{n}$ - подвижность электронов в слабо легированной области, $L_{\mathrm{D}}=\left(\varepsilon_{0} \varepsilon_{s} k T / 2 q^{2} n_{2}\right)^{0.5}$ - дебаевская длина экранирования для слабо легированной области.

Отметим, что выражение (2) получено с учетом результатов работ [13] и [14], т.е. в нем учтены как диффузионные, так и эмиссионные слагаемые в токе, протекающем через слабо легированную область.

Итак, в случае, когда выполнено неравенство $\rho_{\mathrm{c} 2}>\rho_{\mathrm{c} 1}$, контакт будет чисто омическим. В этом случае в слабо легированной области изгиб зон не истощающий, а обогащающий и поэтому все напряжение, приложенное к контакту, будет падать на нейтральном объеме, что и обеспечит омичность контакта.

Величина подвижности электронов $\mu_{n}$ в области слабого легирования рассчитывалась с учетом рассеяния на заряженных примесях, а также междолинных и акустических фононах [15]. Предполагалось, что концентрация дислокаций в слабо легированной области достаточно низка и не влияет на подвижность электронов. Выражения для расчета $\mu_{n}$ приведены в работе [16].

Остановимся далее на анализе температурной зависимости сопротивления $\rho_{\mathrm{c} 2}$. В случае, когда роль диффузионного тока мала, т. е. выполнено неравенство $\left(\frac{L_{\mathrm{D}} A^{*} T}{k \mu_{n} N_{\mathrm{c}}}\right)<1$, температурная зависимость $\rho_{\mathrm{c} 2}$ с учетом того, что $N_{\mathrm{c}}(T)=N_{\mathrm{c} 0}(T / 300)^{3 / 2}$, имеет вид $\rho_{\mathrm{c} 2} \sim \sqrt{T}$, т. е. величина удельного контактного сопротивления растет с увеличением температуры как $\sqrt{T}$. Как показано в работе [13], данное неравенство выполняется в области уровней легирования, когда $n_{2} \gg 10^{15} \mathrm{~cm}^{-3}$. В области низких и промежуточных уровней легирования $\left(\frac{L_{\mathrm{D}} A^{*} T}{k \mu_{n} N_{\mathrm{c}}}\right) \geq 1$ и, как показывает анализ, степень роста $\rho_{\mathrm{c} 2}$ с повышением температуры увеличивается по сравнению с законом $\sqrt{T}$.

На рис. 3 построены теоретические зависимости $\rho_{\mathrm{c} 2}(T)$ с использованием формулы (2), а также низкотемпературного вымораживания электронов, когда учитывается, что концентрация электронов в объеме полупроводника $n_{2}(T)$ определяется при использовании уравнения нейтральности вида

$$
\begin{aligned}
\frac{N_{d}}{1+\exp \left(\left(E_{\mathrm{F}}-E_{d}\right) / k T\right)}=\frac{2}{\sqrt{\pi}} N_{\mathrm{c} 0}\left(\frac{T}{300}\right)^{3 / 2} \\
\times \int_{0}^{\infty} \frac{\kappa^{0.5}}{1+\exp \left(\kappa-E_{\mathrm{F}} / k T\right)} d \kappa,
\end{aligned}
$$

где $E_{d}-$ энергия мелких донорных уровней, $E_{\mathrm{F}}-$ энергия Ферми, $N_{\mathrm{c} 0}$ - эффективная плотность состояний в зоне проводимости при температуре $T=300 \mathrm{~K}, \kappa-$ кинетическая энергия электронов в зоне проводимости, нормированная на $k T$.

Параметром кривых является уровень легирования. В области температур больше $80 \mathrm{~K}$ все зависимости имеют растущий характер. В случае кривой 1 , соответствующей наименьшему уровню легирования $10^{13} \mathrm{~cm}^{-3}$, степень роста $\rho_{\text {с2 }}(T)$ в области повышенных температур наибольшая и составляет 2.4. По мере увеличения уровня легирования она уменьшается и равна соответственно: для $n_{2}=10^{14} \mathrm{~cm}^{-3}-2.1$, для $n_{2}=10^{15} \mathrm{~cm}^{-3}-1.4$, для $n_{2}=10^{16} \mathrm{~cm}^{-3}-1$ и для $n_{2}=10^{17} \mathrm{~cm}^{-3}-0.8$.

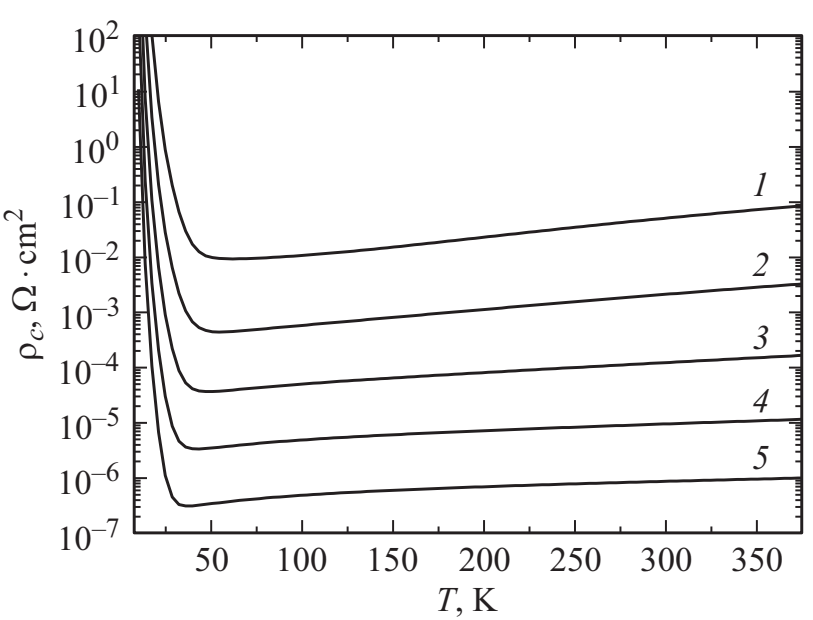

Рис. 3. Теоретические зависимости с использованием формулы (2) и учетом низкотемпературного вымораживания электронов: $n_{2}, \mathrm{~cm}^{-3}: 1-10^{13}, 2-10^{14}, 3-10^{15}, 4-10^{16}$, $5-10^{17}, A^{*}=112 \mathrm{~A} \cdot \mathrm{cm}^{-2} \cdot \mathrm{K}^{-2}, N_{\mathrm{c}}=2.8 \cdot 10^{19} \mathrm{~cm}^{-3}$. 
Вернемся к рис. 1. На нем приведены экспериментальные зависимости $\rho_{\mathrm{c}}(T)$, полученные для образцов $\mathrm{Si}$ со ступенькой легирования, которая создавалась диффузией фосфора на глубину 0.2 мкм. Они были измерены дважды, начиная с гелиевых температур: от температуры 12.5 до $300 \mathrm{~K}$, а также начиная с азотных температур: от температуры 170 до $380 \mathrm{~K}$. Как видно из рисунка, в области $T \geq 170 \mathrm{~K}$ экспериментальные кривые хорошо согласуются между собой. Теоретическая кривая построена по формуле (2), в которой учтено низкотемпературное вымораживание носителей заряда. Достигнуто хорошее согласие между экспериментом и теорией. Необходимо, однако, отметить, что согласие получено при использовании значения объемной концентрации в кремнии, равного $1.6 \cdot 10^{13} \mathrm{~cm}^{-3}$, в то время как исходный уровень легирования составлял $\sim 10^{15} \mathrm{~cm}^{-3}$.

Объяснить такое уменьшение объемной концентрации электронов можно, если предположить, что в подложке $n-\mathrm{Si}$ вследствие релаксации механических напряжений на границе сильно легированного слоя и подложки возникают протяженные и точечные дефекты с достаточно высокими значениями концентрации глубоких уровней акцепторной природы. По этой причине между сильно легированным слоем и подложкой возникает компенсированный слой [17]. Кроме этого палладий, входящий в контактную систему, обладает также акцепторными свойствами и создает в $\mathrm{Si}$ акцепторные центры $[18,19]$. Введение $\mathrm{Pd}$ в $n$-Si приводит либо к уменьшению концентрации электронов, т.е. частичной компенсации при $N_{\mathrm{d}}>N_{\mathrm{Pd}}$, либо к изменению типа проводимости (при $N_{\mathrm{Pd}}>N_{\mathrm{d}}$ ) $[17,18]$, т.е. путем легирования $\mathrm{Pd}$ можно компенсировать значение проводимости низкоомного $\mathrm{Si}$ до собственной [17]. По этой причине вполне возможно уменьшение концентрации электронов в подложке $n$-Si и увеличение вследствие этого $\rho_{\mathrm{c}}$. На акцепторную природу центров указывают также высокая концентрация вакансий в кремнии после термообработки контактных систем. Действительно, концентрация вакансий $N_{v}$ в $\mathrm{Si}$ определяется по данным работ $[17,20,21]$ как

$$
N_{v}=A F \exp (-W / k T)
$$

где $W$ - энергия образования вакансий в $\mathrm{Si}$ изменяется в зависимости уровня легирования кремния фосфором от 4 до 0.6 эВ, уменьшается с ростом концентрации легирующей примеси до $\sim 10^{20} \mathrm{~cm}^{-3}$ и приводит к увеличению равновесной концентрации вакансий на $\sim 2$ порядка за счет комплексообразования ион-фосфора вакансия [21,22]. К уменьшению $W$ приводит также возникновение в решетке $\mathrm{Si}$ локальных упругих напряжений за счет разницы атомных радиусов примеси (Pd) и матрицы $(\mathrm{Si})$. При $R_{\mathrm{Pd}}>R_{\mathrm{Si}}$ вокруг атомов примеси возникают сжимающие напряжения. Это должно уменьшать $W$, увеличивать равновесную концентрацию вакансий и уменьшать концентрацию межузельных атомов. Действительно, $R_{\mathrm{Pd}}=0.137 \mathrm{HM}$, a $R_{\mathrm{Si}}=0.117 \mathrm{Hм}$,

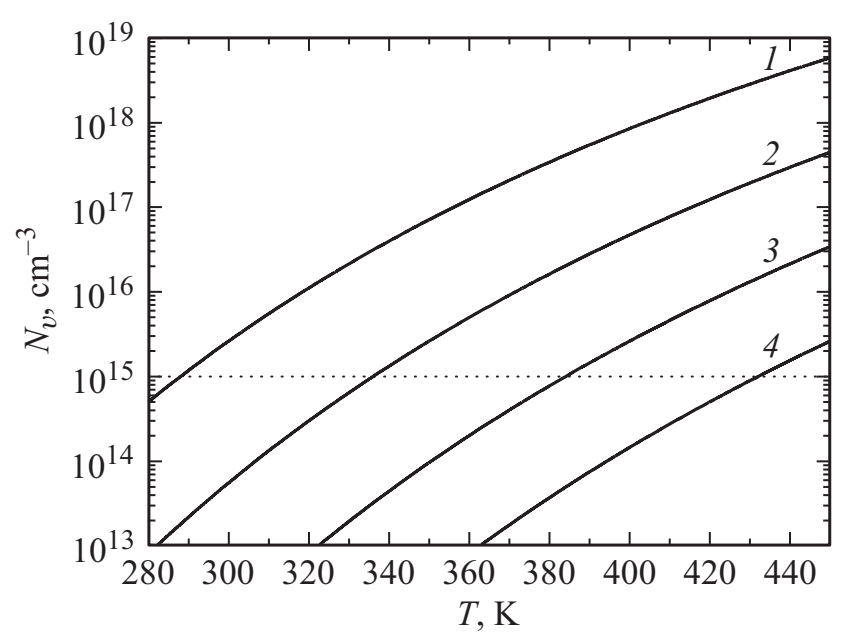

Рис. 4. Зависимости концентрации вакансий $N_{v}$ от температуры (4). $A=10^{22} \mathrm{~cm}^{-3}, F=3 \cdot 10^{3}, W$, эВ: $1-0.6,2-0.7$, $3-0.8,4-0.9$.

$R_{\mathrm{Pd}}>R_{\mathrm{Si}}$, что должно приводить к напряжениям вокруг примеси $(\mathrm{Pd})$ и, следовательно, уменьшению $W$ [23]. Здесь $A-$ коэффициент пропорциональности, зависящий от числа атомов в единице обьема кристалла и от числа пустых мест, в которые может перескочить атом, $F$ - медленно меняющаяся с температурой функция, численное значение которой по порядку величины лежит в пределах $10^{3}-10^{4}$.

Для набора различных значений $W$ зависимость концентрации вакансий $N_{v}$ от температуры $T$ будет определяться зависимостями (4), приведенными на рис. 4. Как видно из рис. 4, при значениях энергии вакансий, лежащих в диапазоне 0.6-0.9 эВ, при температурах, превышающих $280^{\circ} \mathrm{C}$, концентрация вакансий изменяется в широких пределах и может превышать $10^{18} \mathrm{~cm}^{-3}$. Такой концентрации вакансий вполне достаточно для практически полной компенсации кремния, в том числе и сильно легированного. Для подтверждения высказанных предположений были проведены рентгеноструктурные исследования указанных образцов.

\section{4. Структурные исследования}

Для определения дефектного состояния образцов были измерены $\omega$ - и $\omega-2 \theta$-сканы для симметричных рефлексов (111). Из рис. 5 видно, что после диффузии при $900^{\circ} \mathrm{C}$ полуширина дифракционной кривой отражения (ДКО) увеличивается, а также растут интенсивность диффузного рассеяния, „хвосты“ с обеих сторон максимума ДКО. С повышением температуры диффузии до $925^{\circ} \mathrm{C}$ наблюдается уменьшение хвостов диффузного рассеяния с обеих сторон максимума ДКО. Последующее повышение температуры диффузии приводит к сильнейшей асимметрии ДКО, причем преобладающей является диффузная компонента со стороны больших углов. 
Таблица 1. Оценка размеров дефектных областей

\begin{tabular}{c|c|c|c|c}
\hline \multirow{2}{*}{$\begin{array}{c}\text { Образец, } T \\
\text { диффузии, }{ }^{\circ} \mathrm{C}\end{array}$} & \multicolumn{2}{|c|}{$\begin{array}{c}\text { Размеры областей } \\
\text { вакансионных дефектов, нм }\end{array}$} & \multicolumn{2}{|c}{ Размеры областей } \\
& изежузельных дефектов, нм
\end{tabular}

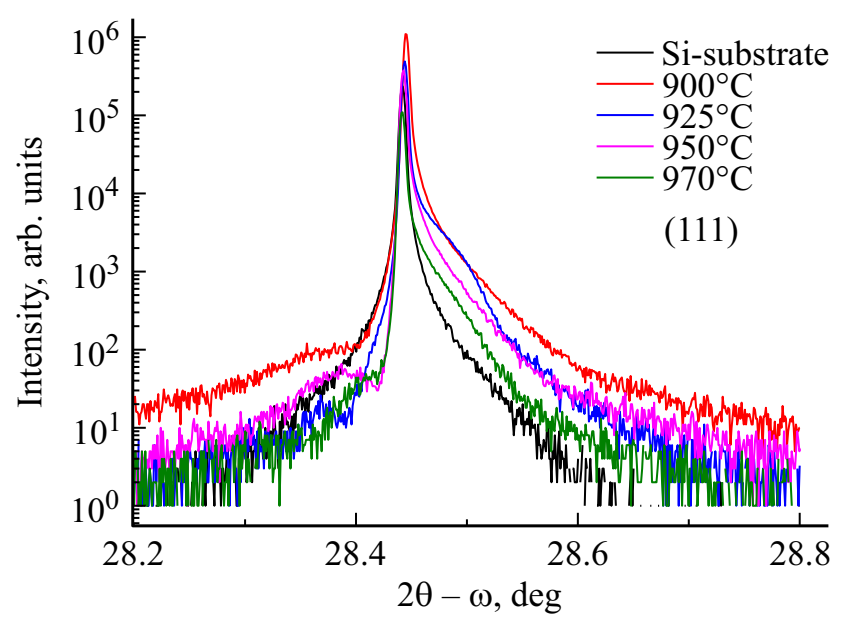

Рис. 5. $2 \theta-\omega$-скан симметричного рефлекса кремния (111).

Для анализа ДКО использовались соотношения для преобразования угловых координат в координаты в пространстве обратной решетки:

$$
\begin{aligned}
\frac{q_{x}}{2 \pi} & =\frac{1}{\lambda}\left(\cos \omega-\cos \left(2 \omega^{\prime}-\omega\right)\right) \Rightarrow q_{x} \\
& =\frac{2 \pi}{\lambda}\left(\cos \omega-\cos \left(2 \omega^{\prime}-\omega\right)\right), \\
\frac{q_{z}}{2 \pi} & =\frac{1}{\lambda}\left(\sin \omega-\sin \left(2 \omega^{\prime}-\omega\right)\right) \Rightarrow q_{z} \\
& =\frac{2 \pi}{\lambda}\left(\sin \omega-\sin \left(2 \omega^{\prime}-\omega\right)\right) .
\end{aligned}
$$

Здесь $\lambda$ - длина волны рентгеновского излучения, которая соответствует $\mathrm{Cu}_{K \alpha} ; q_{x}, q_{z}$ - координаты в пространстве обратной решетки, $\omega, \omega^{\prime}-$ соответственно углы падения и отражения.

Для анализа типа дефектов в образцах использовались высокоразрешающие $2 \theta-\omega$ - и $\omega$-сканы. Из $2 \theta-\omega$-сканов были построены зависимости $I=I q_{z}^{2}$ и $I=I q_{z}^{3}$, приведенные на рис. $6, a$ и $6, b$, соответственно.

Из кривых, приведенных на рис. 6, видно, что в данных образцах присутствуют дефекты как вакансионного типа $\left(q_{z}<0\right)$, так и межузельного типа $\left(q_{z}>0\right)$. При температуре диффузии $900^{\circ} \mathrm{C}$ наблюдается увеличение концентрации дефектов обоих типов, хотя межузельные дефекты превалируют. При дальнейшем росте температуры диффузии наблюдается уменьшение количества дефектов вакансионного типа. Концентрация основных дефектов типа межузельных атомов также имеет тенденцию спада с возрастанием температуры диффузии фосфора [24]. Такой спад может быть связан с увеличением числа дислокаций в образцах с ростом температуры диффузии [25].

Анализ $\omega$-сканов, снятых в направлении, перпендикулярном вектору дифракции, проводился с помощью построения $\log I=f\left(\log q_{x}\right)$, приведенных на рис. 7, $a$ и $b$ соответственно. Из положення максимумов распределения диффузного рассеяния кривых на рис. 6 были найдены распределения дефектов по размерам (табл. 1). Из значений полуширины $\omega$-сканов была проведена оценка плотности дислокаций (табл. 2). Оценки показывают, что полученные нами размеры областей вакансионного и межузельного типов соответствуют данным работы [26].

Из табл. 2 видно, что в исходной пластине плотность дислокаций $\sim 2.2 \cdot 10^{5} \mathrm{~cm}^{-2}$, что типично для сильно легированного $\mathrm{Si}[25,27]$. В результате возрастания температуры диффузии, вследствие роста механических напряжений сжатия в пластине $\mathrm{Si}$, наблюдается изменение плотности дислокаций. В области сжатия возникает повышенная концентрация вакансий и пониженная межузельных атомов [25].

Затем на эти пластины $\mathrm{Si}$ наносились пленки металлов: Pd толщиной 30 нм, Ті толщиной $60 \mathrm{Hм} \mathrm{и} \mathrm{Au}$ толщиной 120 нм. Вжигание контактной металлизации проводилось при $T=350^{\circ} \mathrm{C}$ (образцы 900, $925^{\circ} \mathrm{C}$ ) и

Таблица 2. Оценка плотности дислокаций

\begin{tabular}{c|c|c}
\hline $\begin{array}{c}\text { Образец, } T \\
\text { диффузии, }\end{array}$ & $\begin{array}{c}\text { Ширина на } \\
\text { полувысоте пика } \\
\text { (град) }\end{array}$ & $\begin{array}{c}\text { Плотность } \\
\text { дислокаций, } \\
\text { см }^{-2}\end{array}$ \\
\hline $\mathrm{Si}($ исходный) & 0.01033 & $2.20 \cdot 10^{5}$ \\
900 & 0.00210 & $9.10 \cdot 10^{3}$ \\
925 & 0.00529 & $5.77 \cdot 10^{4}$ \\
950 & 0.00429 & $3.80 \cdot 10^{4}$ \\
970 & 0.01799 & $6.68 \cdot 10^{5}$
\end{tabular}



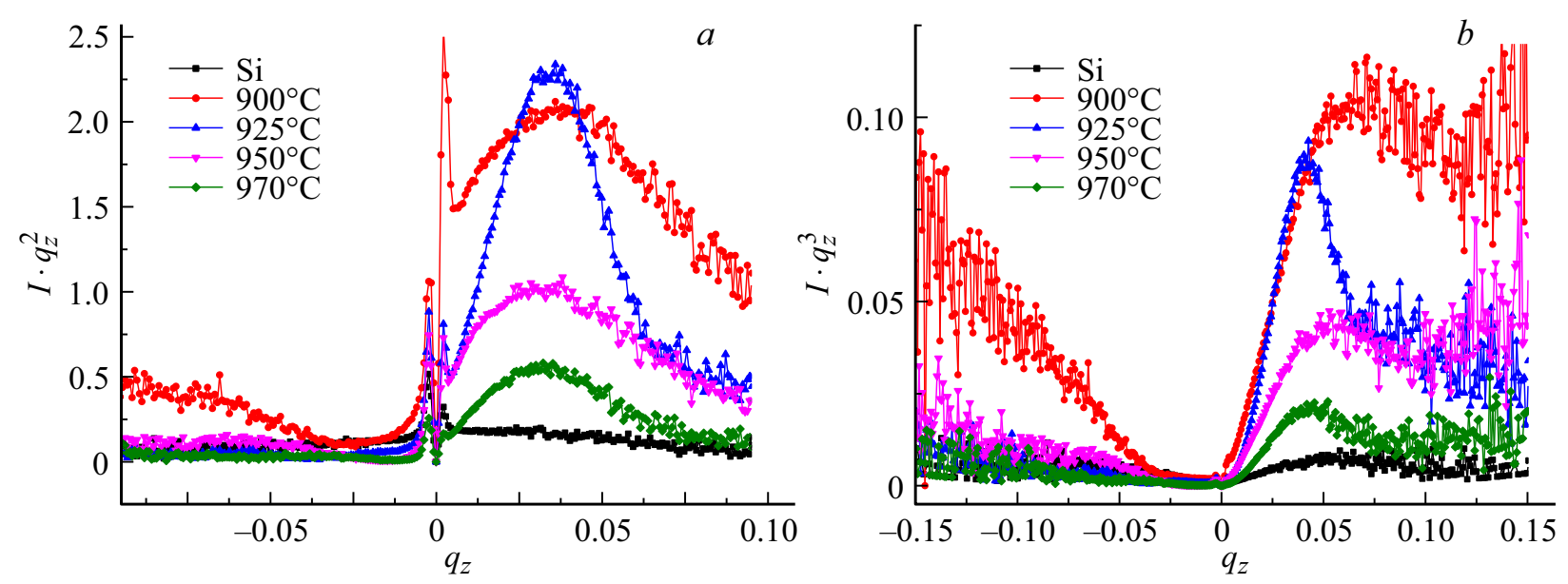

Рис. 6. Сравнение построений $I=I q_{z}^{2}(a)$ и $I=I q_{z}^{3}(b)$, полученных из $2 \theta-\omega$-сканов.
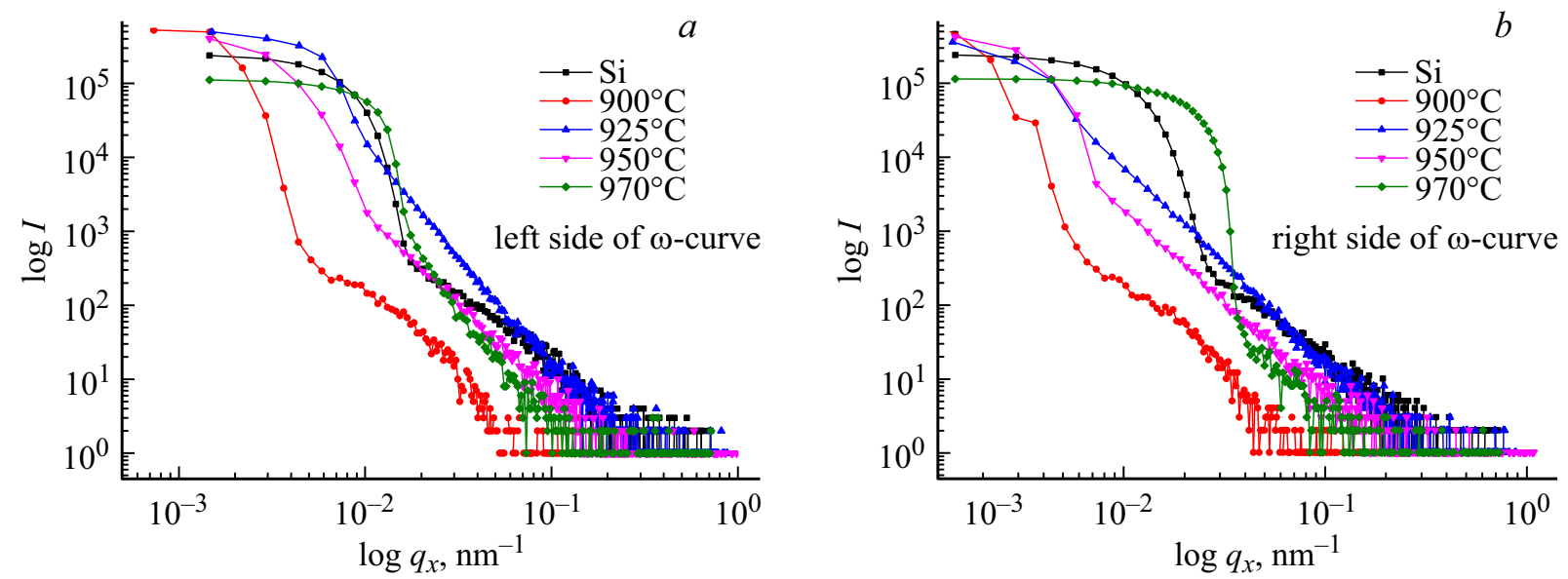

Рис. 7. Перестроенные в координатах $\log I\left(\log q_{x}\right)$ левая $(a)$ и правая $(b)$ стороны $\omega$-сканов, снятых в направлении, перпендикулярном вектору дифракции.

$T=450^{\circ} \mathrm{C}$ (образцы 950 и $\left.970^{\circ} \mathrm{C}\right)$ в течение 10 мин. На этих образцах была определена плотность дислокаций, значения которой приведены в табл. 3 .

По смещению пика от рефлекса (111) $\mathrm{Si}$ на $2 \theta-\omega$-сканах были получены относительные деформации в образцах, прошедших диффузию и с вожженными контактами (табл. 4), и из табл. 3 и 4 рассчитаны величины внутренних механических напряжений $\sigma[28]$. Видно, что низкотемпературный отжиг приводит к росту $\sigma$ и плотности дислокаций по сравнению с образцами, прошедшими только диффузию, что свидетельствует о существенной перестройке ансамблей точечных и линейных дефектов, а также генерации дислокаций при низкотемпературной обработке. При этом будут преобладать те дефекты, для образования которых потребуется меньше затрат энергии.

Таблица 3. Оценка плотности дислокаций

\begin{tabular}{|c|c|c|c|c|c|}
\hline $\begin{array}{c}\text { Образец, } T \\
\text { диффузии, }{ }^{\circ} \mathrm{C}\end{array}$ & $\begin{array}{c}T \text { отжига } \\
{ }^{\circ} \mathrm{C}\end{array}$ & $\begin{array}{c}\text { Ширина } \\
\text { на полувысоте } \\
\text { пика * (град) }\end{array}$ & $\begin{array}{c}\text { Ширина } \\
\text { на полувысоте } \\
\text { пика }{ }^{* *} \text { (град) }\end{array}$ & $\begin{array}{c}\text { Плотность } \\
\text { дислокаций* } \\
\text { см }^{-2}\end{array}$ & $\begin{array}{c}\text { Плотность } \\
\text { дислокаций }^{* *}, \\
\text { см}^{-2}\end{array}$ \\
\hline $\begin{array}{l}900 \\
925 \\
950 \\
970\end{array}$ & $\begin{array}{l}350 \\
350 \\
450 \\
450\end{array}$ & $\begin{array}{l}0.00210 \\
0.00529 \\
0.00429 \\
0.01799\end{array}$ & $\begin{array}{l}0.02064 \\
0.00436 \\
0.00995 \\
0.00407\end{array}$ & $\begin{array}{l}9.10 \cdot 10^{3} \\
5.77 \cdot 10^{4} \\
3.80 \cdot 10^{4} \\
6.68 \cdot 10^{5}\end{array}$ & $\begin{array}{l}8.79 \cdot 10^{5} \\
3.92 \cdot 10^{4} \\
2.04 \cdot 10^{5} \\
3.42 \cdot 10^{4}\end{array}$ \\
\hline
\end{tabular}

Примечание. ${ }^{*}$ исходная пластина кремния со сформированным $n^{+}-\mathrm{Si}$-слоем; ** тот же образец после нанесения металлизации и отжига. 
Таблица 4. Расчет величины $\sigma$ по данным работы [28] и $\varepsilon$

\begin{tabular}{|c|c|c|}
\hline $\begin{array}{c}\text { Образец, } T \\
\text { диффузии, }{ }^{\circ} \mathrm{C}\end{array}$ & $\varepsilon, \%$ & $\begin{array}{c}\sigma=\sigma_{0} \cdot \varepsilon \cdot 100 \%, \text { Па } \\
\left(\sigma_{0}=187.8 \cdot 10^{9} \text { Па }[28]\right)\end{array}$ \\
\hline $\mathrm{Si}$ & $-1.44 \cdot 10^{-5}$ & $-2.70 \cdot 10^{6}$ \\
\hline 900 & $-1.10 \cdot 10^{-4}$ & $-2.07 \cdot 10^{7}$ \\
\hline 925 & $-8.33 \cdot 10^{-5}$ & $-1.56 \cdot 10^{7}$ \\
\hline 950 & $-3.86 \cdot 10^{-5}$ & $-7.25 \cdot 10^{6}$ \\
\hline 970 & $-1.36 \cdot 10^{-4}$ & $-2.55 \cdot 10^{7}$ \\
\hline С контактами & & \\
\hline 900 (отжиг при $350^{\circ} \mathrm{C}$ ) & $-3.41 \cdot 10^{-5}$ & $-6.40 \cdot 10^{6}$ \\
\hline 925 (отжиг при $1350^{\circ} \mathrm{C}$ ) & $-1.53 \cdot 10^{-4}$ & $-2.87 \cdot 10^{7}$ \\
\hline 950 (отжиг при $450^{\circ} \mathrm{C}$ ) & $-8.17 \cdot 10^{-5}$ & $-1.53 \cdot 10^{7}$ \\
\hline 970 (отжиг при $\left.350^{\circ} \mathrm{C}\right)$ & $-1.57 \cdot 10^{-4}$ & $-2.95 \cdot 10^{7}$ \\
\hline
\end{tabular}

Таким образом, из приведенных данных следует, что компенсация кремния связана с:

1) диффузией $\mathrm{Pd}$ при $T_{\mathrm{ann}} 350^{\circ} \mathrm{C}$, или $450^{\circ} \mathrm{C}$ из омического контакта $\mathrm{Au}-\mathrm{Ti}-\mathrm{Pd}-n^{+}-n-\mathrm{Si}$;

2) высокой плотностью точечных дефектов (вакансий) в $\mathrm{Si}$, возникающей при термообработке;

3) высокой плотностью дислокаций, возникающей при диффузии и термообработке.

\section{5. Заключение}

Представленные в работе результаты и их анализ свидетельствуют о том, что исследованные кремниевые структуры $\mathrm{Au}-\mathrm{Ti}-\mathrm{Pd}-n^{+}-n-\mathrm{Si}$ являются омическими контактами в области температур от 4.2 до $380 \mathrm{~K}$. Установлено, что величина удельного контактного сопротивления $\rho_{\mathrm{c}}$ в области $T \geq 80 \mathrm{~K}$ растет по степенному закону при увеличении температуры. Степень роста растет при уменьшении объемного уровня легирования от 0.8 при достаточно высоких уровнях легирования $\left(\sim 10^{17} \mathrm{~cm}^{-3}\right)$ до 2.4 при низких уровнях легирования $\left(\sim 10^{13} \mathrm{~cm}^{-3}\right)$.

Показано, что в промежуточном слое между сильно легированной областью и объемом происходит компенсация материала объема, связанная, в частности, с образованием большой концентрации вакансий из-за большой плотности дислокаций, возникающих при диффузии и термообработке.

Образование дислокаций и дефектов вакансионного типа подтверждается данными рентгеновских исследований.

\section{Список литературы}

[1] С.М. Зи. Физика полупроводниковых приборов. (М., Мир, 1984) ч. 1.

[2] S.E. Swirhun, R.M. Swanson. IEEE Electron Dev. Lett., 7 (3), 155 (1986).

[3] D.K. Schroder. Semiconductor material and device characterization. 3 edn (IEEE Press. John Wiley \& Sons, Inc., 2006).
[4] A.E. Belyaev, N.S. Boltovets, R.V. Konakova, Ya.Ya. Kudryk, A.V. Sachenko, V.N. Sheremet. SPQEO, 13 (4), 436 (2010).

[5] А.В. Саченко, А.Е. Беляев, В.А. Пилипенко, Т.В. Петлицкая, В.А. Анищик, Н.С. Болтовец, Р.В. Конакова, Я.Я. Кудрик, А.О. Виноградов, В.Н. Шеремет. ФТП, 48 (3), 509 (2014).

[6] У.М. Кулиш, А.П. Вяткин. Изв. вузов. Физика. 6, 157 (1965).

[7] А.Е. Беляев, В.Н. Бессолов, Н.С. Болтовец, Ю.В. Жиляев, В.П. Кладько, Р.В. Конакова, А.В. Кучук, А.В. Саченко, В.Н. Шеремет. Физико-технологические проблемы нитридгаллиевой электроники (Киев, Наук. думка, 2016).

[8] Н.С. Давыдова, Ю.З. Данюшевский. Диодные генераторы и усилители СВЧ (М., Радио и связь, 1986).

[9] N.S. Boltovets, V.V. Kholevchuk, R.V. Konakova, V.F. Mitin, E.F. Venger. Sensors Actuators A: Physical, 92 (1-3), 191 (2001).

[10] В.Н. Алфеев. Полупроводники, сверхпроводники и параэлектрики в криоэлектронике: Свойства и применение в криоэлектронных интегральных схемах и приборах структур на основе контактов полупроводников, сверхпроводников и параэлектриков (М., Сов. радио, 1979).

[11] А.Е. Беляев, Н.С. Болтовец, В.П. Кладько, Р.В. Конакова, О.И. Любченко, А.В. Саченко, Н.В. Сафрюк, В.В. Шинкаренко, В.А. Пилипенко, Т.В. Петлицкая, А.А. Ходин, П.Н. Романец. В кн.: Матер. VI Межлунар. науч.-практ. конф. „Структурна релаксация в твердих телах“ (Винница, Україна, 2018) с. 213.

[12] V.P. Klad'ko, L.I. Datsenko, J. Bak-Misiuk, S.I. Olikhovskii, V.F. Machulin, I.V. Prokopenko, V.B. Molodkin, Z.V. Maksimenko. J. Phys. D: Appl. Phys., 34, A87 (2001).

[13] R.K. Kupka, W.A. Anderson. J. Appl. Phys., 69 (6), 3623 (1991).

[14] G. Brezeanu, C. Cabuz, D. Dascalu, P.A. Dan. Sol. St. Electron., 30 (5), 527 (1987).

[15] D.K. Ferry. Phys. Rev. B, 14 (4), 1605 (1976).

[16] A.V. Sachenko, A.E. Belyaev, N.S. Boltovets, R.V. Konakova, Ja.Ja. Kudryk, S.V. Novitski, V.N. Sheremet, J. Li, S.A. Vitusevich. J. Appl. Phys. III (8), 083701 (2012).

[17] Б.И. Болтакс, М.К. Бахадырханов, С.М. Городецкий, Г.С. Куликов. Компенсированный кремний (Л., Наука. Ленингр. отд-ние, 1972).

[18] М.С. Юнусов. Физические явления в кремнии, легированном элементами платиновой группы (Ташкент, ФАН, 1983).

[19] Физика и материаловедение полупроводников с глубокими уровнями, под ред. В.И. Фистуля (М., Металлургия, 1987).

[20] В.И. Фистуль. Введение в физику полупроводников (М., Высш. шк., 1984).

[21] Р. Смит. Полупроводники, пер. с англ. (М., Мир. 1982).

[22] Б.И. Болтакс. Дифбузия и точечные дефекты в полупроводниках (Л., Наука. Ленингр. отд-ние, 1972).

[23] С.С. Горелик, М.Я. Дашевский. Материаловедение полупроводников и диэлектриков (М., Металлургия. 1988).

[24] В.Т. Бублик, С.Ю. Мацнев, К.Д. Щербачёв, М.В. Меженный, М.Г. Мильвидский, В.Я. Резник. ФТТ, 45 (10), 1825 (2003).

[25] К. Рейви. Дебекты и примеси в полупроводниковом кремнии (М., Мир, 1984). 
[26] В.С. Васильев, В.Ф. Киселев, Б.Н. Мукашев. Дефбекты в кремнии и на его поверхности (М., Наука, 1990).

[27] М.Г. Мильвидский, В.Б. Освенский. Структурные дефекты в монокристаллах полупроводников (М., Металлургия, 1984).

[28] A. Dargys, J. Kundrotas. Handbook on physical properties of $\mathrm{Ge}, \mathrm{Si}, \mathrm{GaAs}$ and InP (Vilnius, Science and Encyclopedia Publishers, 1994).

Редактор А.Н. Смирнов

\section{Features of the temperature dependence of the specific contact resistance of diffusion silicon strucrures \\ $\mathrm{Au}-\mathrm{Ti}-\mathrm{Pd}-n^{+}-n-\mathrm{Si}$}

A.E. Belyaev' ${ }^{1}$, N.S. Boltovets ${ }^{2}$, V.P. Klad'ko', N.V. Safryuk-Romanenko ${ }^{1}$, A.I. Lubchenko ${ }^{1}$, V.N. Sheremet ${ }^{1}$, V.V. Shynkarenko ${ }^{1}$, A.S. Slepova ${ }^{2}$, V.A. Pilipenko ${ }^{3}$, T.V. Petlitskaya ${ }^{3}$, A.S. Pilipchuk ${ }^{4}$, R.V. Konakova ${ }^{1}$, A.V. Sachenko ${ }^{1}$

${ }^{1}$ Lashkaryov Institute of Semiconductor Physics, National Academy of Sciences of Ukraine, 03028 Kiev, Ukraine ${ }^{2}$ State Enterprise Research Institute "Orion“, 03057 Kiev, Ukraine 3 JSC „INTEGRAL" - Holding Management Company, 220108 Minsk, Republic of Belarus

${ }^{4}$ Institute of Physics, National Academy of Sicences of Ukraine, 03028 Kiev, Ukraine

Abstract Temperature dependences of the specific contact resistance of silicon with a doping step were measured and theoretically described. The measurements were carried out under the temperature range from 4.2 to $380 \mathrm{~K}$. It was established that the contacts of studied $\mathrm{Au}-\mathrm{Ti}-\mathrm{Pd}-n^{+}-n$-Si structures are ohmic. It was shown that the minimum $\rho_{c}$ value is realized at $T=75 \mathrm{~K}$, and its value increases both with temperature decrease (due to the freezing effect) and increase (due to the presence of an electron enrichment layer at the boundary with the bulk material). It was established that in the near-contact region, in a layer with a thickness of the micron order, there is a strong decrease of electrons in the volume concentration due to the compensation of silicon by deep acceptors, formed by sufficiently high concentration of vacancies during stress relaxation and the appearance of a high dislocation density, as well as because of their diffusion from contact after warming up to $450^{\circ} \mathrm{C}$. The fact of the existence of vacancy-type defects is confirmed by $X$-ray measurements. The dislocation density in the studied structures was also estimated fron $X$-ray measurements. 